\title{
Los sistemas de información web en las bibliotecas públicas: la situación en la región de Murcia
}

\author{
Francisco Javier García Gómez y Antonio Díaz Grau \\ Biblioteca Pública Municipal de San Javier (Murcia)
}

\section{1. Resumen}

Se analiza con detalle el posicionamiento de las bibliotecas públicas de la Región de Murcia en Internet, así como las principales características de sus webs.

Palabras Clave: Sistemas de información Web. Bibliotecas públicas municipales. Bibliotecas digitales. Región de Murcia.

\section{2. Abstract}

The situation and the main characteristics of Internet access to the public libraries of the Region of Murcia is carefully analyzed.

Keywords: Web information Systems. Local public libraries. Digital libraries. Internet. Region of Murcia (Spain).

\section{Introducción y contexto}

La tecnología Web aplicada al mundo de la información, y más concretamente al entorno de las unidades de información y documentación, se ha convertido actualmente en una de las más importantes aportaciones de las tecnologías en el ámbito social y cultural. No cabe duda que esta nueva tecnología supone, va a seguir suponiendo, nuevos requerimientos y nuevas posibilidades en estos centros documentales, tanto a la hora de proporcionar información a sus usuarios como a la hora de proporcionar nuevos servicios relacionados con entornos virtuales y digitales. Hay que tener en cuenta que la nueva sociedad digital o sociedad de la información, en la cual nos encontramos inmersos, establece nuevas pautas de desarrollo y motivación en todos los ámbitos y especialmente en el de las unidades de documentación. En este proceso de innovación tecnológica protagoniza un papel fundamental la World Wide Web (WWW) y, por ende, Internet.

En el ámbito concreto de las bibliotecas públicas es especialmente interesante este aspecto ya que será la WWW la que permitirá desarrollar los denominados sistemas de información web (en adelante, SIW) para estas unidades de informa- 
ción. Un SIW puede concebirse como un conjunto de recursos, servicios y prestaciones en modo digital, estructurados en diferentes sitios web, organizados y ofrecidos en línea a los usuarios siendo accesibles a través de redes de telecomunicaciones para, de esta manera, satisfacer las necesidades informativas y documentales de los mismos en un entorno virtual, interactivo, amigable y accesible en cualquier momento. Por ello, hay que tener en cuenta que un SIW de una biblioteca no es simplemente una página web, más o menos bonita, mejor o peor diseñada, sobre la biblioteca, en la que se muestran datos sobre la misma. Es mucho más: Es una nueva forma de proporcionar información y conocimiento a los usuarios; es hacerles accesibles aquellas informaciones y colecciones que en el ámbito real y presencial no están totalmente accesibles; es, en definitiva, un nuevo medio de proporcionar todo tipo de información de interés real y/o potencial para cualesquiera usuarios. De este modo, la nueva biblioteca pública que surge en este marco de cooperación con el mundo de Internet, es la respuesta a la interacción que con su entorno y con las necesidades de sus usuarios establece la institución documental que conocemos como biblioteca pública, en el contexto de la sociedad de la información. Ambos conceptos están ligados: la biblioteca digital (1) surge dentro de la sociedad de la información; y ésta, para desarrollarse de forma democrática y sostenible, necesita una biblioteca pública vigorosa, actual, operativa y al alcance de todos (Agustín, 1998, p. 48).

La implicación de Internet en la biblioteca pública española (2) es de suma importancia por lo que conlleva a la hora de proporcionar más y mejores servicios a los ciudadanos en un enfoque claramente de servicio social y cultural. Esta interrelación es cada vez mayor hasta el punto de que muchas de estas bibliotecas comienzan ya a desarrollar auténticos SIW de forma que amplían las prestaciones y posibilidades que, antaño ofrecían de manera presencial, trasladando sus servicios y recursos documentales e informativos al nuevo escenario digital y virtual hacia donde evoluciona la biblioteca del futuro.

¿Será la biblioteca pública de mañana diferente a la de hoy? Es esta una cuestión que en los últimos años, en la última década, cobra gran interés y es punto de discusión entre los estudiosos del tema. El desarrollo que se está produciendo en todos los sistemas de información, cada vez más sofisticados y perfeccionados, y la implantación de las herramientas tecnológicas e informáticas más novedosas están cambiando los hábitos de trabajo, como no, de estas bibliotecas. Sin embargo, no es raro todavía encontrarnos con bibliotecas que sólo presentan materiales y colecciones bibliográficas y usuarios y lectores. Y es que, aunque la nueva tecnología aplicada a los procesos de información ha cambiado la esencia de los servicios de información y documentación, los planteamientos de trabajo siguen siendo los mismos, y subyace en ello una situación de resistirse a los cambios fundamentales del contexto social y cultural en el que nos encontramos inmersos (3). Aún así, estos

Scire. $8: 2$ (jul.-dic. 2002) 91-116. 
inconvenientes no han impedido a las bibliotecas públicas españolas participar en el fenómeno Internet porque, al contrario de lo que se pueda pensar, con Internet y el desarrollo de eficaces SIW, estas bibliotecas tienen la posibilidad de ser mucho más importantes de lo que se pueda suponer; puedan llegar a convertirse en auténticos centros de información para la comunidad a la que sirven (4).

Teniendo en cuenta estas consideraciones, procedemos a realizar un estudio y análisis de las principales características de los SIW existentes actualmente en las bibliotecas públicas de la Región de Murcia.

\section{Metodología y objetivos}

En la presente comunicación analizamos la presencia de las bibliotecas públicas de la Región de Murcia en la red Internet a través de sus SIW. De esta manera, presentamos cuál es el estado actual de servicios, fuentes y recursos de información en línea de los SIWs de dichas bibliotecas públicas. El resultado del análisis ofrece una visión general de las bibliotecas públicas murcianas que cuentan con SIWs desarrollados, al tiempo que ofrecemos una visión detallada de las principales características de cada uno de ellos, dando a conocer los recursos que ofrecen a los usuarios.

Para llevar a cabo el estudio de dichos SIWs procedimos a visitarlos, analizando su composición, estructura y contenidos. La realización de este estudio, análisis y evaluación de los SIWs las hemos efectuado mediante la visita directa, navegando por entre la información que ofrecían y actuando como lo haría cualquier usuario, es decir, accediendo desde la web principal o inicial. Desde allí, recorrimos todas las secciones, servicios, enlaces y sitios web que los conformaban centrando nuestra atención sobre sus elementos formales y de contenido. En este sentido, realizamos un estudio comparativo de las prestaciones, servicios y deficiencias o lagunas detectadas en su caso para, de esta forma, extraer unas conclusiones que nos permitieran apreciar la calidad y "usabilidad" (5) de su estructura, presencia, claridad y contenidos. No obstante, hay que tener en cuenta que los webs de estas bibliotecas son aún jóvenes y, al igual que cualquier tipo de recurso informativo que se encuentra en Internet, son susceptibles de ser continuamente renovados y actualizados, por lo que la información que ofrecemos de ellos debe tomarse en su justa medida, es decir, como datos parciales y no definitivos de una realidad cambiante y dinámica.

\section{Estudio y análisis de los SIW}

El estudio lo realizamos durante los meses de septiembre, octubre y noviembre de 2.001. En este periodo de tiempo tan sólo tres bibliotecas murcianas presentan SIWs desarrollados: la Biblioteca Regional de Murcia y las bibliotecas públicas

Scire. $8: 2$ (jul.-dic. 2002) 91-116. 
municipales de Cieza y Jumilla. También tenemos constancia de la existencia de proyectos de trabajo en marcha para el desarrollo de estos sistemas en otras bibliotecas municipales de la Región de Murcia (Lorca, Puerto Lumbreras y Los Alcázares, entre otras). Hemos observado que los webs de estas bibliotecas pretenden proporcionar información de forma exhaustiva, así como facilitar la navegación por la misma permitiendo interrogar sus catálogos y bases de datos. Con los servicios que ofrecen, permiten agilizar determinadas necesidades de información de los usuarios, además de agilizar ciertos procesos de gestión documental. Por tanto, estas bibliotecas han encontrado en Internet un medio idóneo para elaborar, procesar, organizar, difundir información y otros servicios añadidos.

\section{1. EI SIW de la Biblioteca Pública Municipal de Cieza}

El SIW de la biblioteca pública municipal de Cieza — http://ayuntamiento.cieza.net/educacionycultura/biblioteca/- se integra en un ambicioso proyecto de información digital y virtual sobre la localidad y otros servicios más globales bajo el nombre de CiezaNet — http://www.cieza.net—, a través del cual, se quiere concebir a la localidad de Cieza como una auténtica "ciudad telemática". Esta biblioteca pública nos presenta un web bien estructurado y funcional, perfecto para sus propósitos. La página principal está diseñada a modo de directorio en el que, tras el nombre de la biblioteca, presenta un índice general de contenido mediante enlaces internos, que consigue que de un solo vistazo se conozca el contenido y posibilidades del web. Los servicios están agrupados en siete "unidades" —información general, biblioteca virtual, servicios, recursos de interés bibliotecario, catálogos "OPAC", guías y novedades y BiblioPeque—, grupos de servicios todos ellos que desglosaremos más adelante. Hay que mencionar aquí una consideración: presentar los servicios en conjuntos temáticos facilita su comprensión por parte del usuario, que fácilmente conoce qué puede hacer y cómo lo puede hacer, sin tener que ir de enlace a enlace "investigando". Desde la web principal también se accede al buzón de sugerencias, único enlace, junto con el de BiblioPeque, que viene con una pequeña imagen asociada también sensible. Hacemos alusión a lo de las imágenes, porque un web lleno de imágenes para hacerlo más atractivo, además de distraer a quien lo consulta, ocasiona tardanza en su descarga desde los ordenadores personales o institucionales que lo rescatan de la Red, tardanza ésta que puede inducir al usuario a consultar otra fuente más rápida (6). El primer grupo temático que vamos a analizar es el de Información general, grupo que se desglosa en:

1. Presentación: Ofrece información dividida en dos bloques. El primer bloque, bajo el título de presentación, contiene la definición de biblioteca pública y cuatro fotografías del interior con pie de texto explicativo. El segundo bloque, bajo el título de ¿por qué nuestro nombre?, contiene 
la biografía del santo que da nombre a la biblioteca pública y referencias a varias obras afines al tema.

2. Historia: Breve historia de la biblioteca con dos fotos relativas con pie explicativo.

3. Situación: Contiene la dirección, números de teléfono y fax y ofrece un plano o mapa de la ciudad a través de un enlace, donde se localiza la biblioteca en la ciudad. Además cuenta con una foto de una fachada de la biblioteca.

4. Horario: Horarios durante todo el año.

5. Carné de lector: Presenta esquemáticamente los requisitos para tener el carnet y para qué sirve éste. Ofrece la posibilidad de profundizar en el tema mediante un enlace al reglamento de la biblioteca, concretamente al apartado correspondiente al servicio de préstamo.

6. Reglamentación y legislación: Presenta dos enlaces internos a las dos partes temáticas en las que el servicio está dividido: reglamento y legislación. La parte de reglamento empieza con un índice temático de contenido basado en enlaces internos. En cuanto a la parte de legislación, ésta se compone de una lista de títulos legales que enlazan con su texto integro.

7. Fondos: Se presenta un simple cuadro con los tipos documentales existentes y el número de unidades de cada unos de ellos.

El segundo grupo temático es el de Servicios, grupo que se desglosa en:

1. Préstamo: Carece de índice previo y exige recorrer el web para hacerse una idea de su contenido, lo que supone una incomodidad y una falta de uniformidad de criterios a la hora de presentar la información en los distintos webs del sistema. La información está dividida en tres bloques numerados. El primero es el de préstamo domiciliario, con información esquemática sobre las condiciones del mismo, y al cual se llega también desde el enlace "más información" de la sección "carnet de lector" del primer bloque temático "Información general". A su vez existe un enlace del tipo "más información" que nos lleva hasta el sitio "Reglamento y Legislación" del primer grupo ya visto (7). El segundo bloque es el de préstamo interbibliotecario: ofrece su definición, procedimiento y condiciones de uso. Hay un enlace bajo el nombre "préstamo interbibliotecario" desde el que se puede solicitar dicho préstamo — ejemplo de interactividad con un formulario tipo, esquemático y simple. Bajo nuestro punto de vista, debería titularse el enlace solicitud de préstamo interbibliotecario con el fin de explicar el fin de dicho enlace. El tercer bloque es el de servicio de reserva, en el que se da una definición y se ofrece un enlace interno a una solicitud de reserva de documentos para préstamo. 
2. Información bibliográfica: En este apartado se presenta un índice inicial a las páginas "Cómo utilizar el OPAC", "Consulta directa" y "Consulta a través de Internet". No ofrece formación interactiva.

3. Hemeroteca: Se ofrece una lista por tipo de publicación periódica y dentro de cada tipo, en su caso, una clasificación temática con los títulos disponibles. No presenta enlaces directos a estas publicaciones, aunque luego sí los presenta dentro del grupo temático biblioteca virtual.

4. “Pregunte, las bibliotecas responden": Cuenta con un índice con enalces a los dos apartados de la sección "Pregunte, las bibliotecas responden" y un enlace directo al web del mismo título. En el primer bloque temático se explica qué es el servicio, cómo funciona y quién lo sostiene, ya que es un servicio gestionado desde la Biblioteca Regional de Murcia. El segundo enlace es con el servicio en red que ofrece dicha biblioteca. Se trata de un servicio de información bibliográfica y de referencia interactivo.

5. Mediateca: Se explican las condiciones de uso de este servicio y qué ofrece, (acceso a bases de datos, CD-ROMs y demás software y hardware de la biblioteca). Desde este web no se accede a los diferentes usos del servicio.

6. Desideratas: Ofrece un formulario para pueda enviar solicitudes.

El tercer grupo temático a analizar es el de Catálogos "OPAC", y se desglosa en:

1. De la biblioteca: Se ofrece acceso al OPAC de la biblioteca vía Internet.

2. De otras bibliotecas: Este es un recurso importante. Permite acceder a los OPAC de la Biblioteca Nacional, la Biblioteca Regional de Murcia, la Universitaria de Murcia, las Bibliotecas Públicas del Estado y a los de otras bibliotecas públicas y universitarias. Un usuario puede conseguir los datos completos y exhaustivos de la obra de un autor, conseguir una bibliografía sobre cualquier tema, etc. Un bibliotecario puede rescatar catalogaciones de libros y otros documentos para su propio catálogo, ganando tiempo para otras tareas.

El cuarto grupo temático se denomina Biblioteca virtual y presenta su información en un solo web encabezado con el ya comentado índice sensible de contenidos con enlaces internos a las respectivas secciones:

1. Obras de referencia: Nos presenta una lista sensible de los siguientes recursos virtuales: diccionarios — cinco de español, tres de inglés, uno de francés, portugués, catalán, italiano y alemán, y 10 multilingües-, un anuario, cuatro atlas, cuatro enciclopedias y nueve directorios.

2. Periódicos electrónicos: Se estructura este apartado en siete grupos de recursos que encauzan las posibles necesidades de información que sobre el asunto se tengan: "Buscadores de Prensa" (seis enlaces), "Agencias, 
titulares y búsqueda de noticias" (cuatro enlaces), "Regionales", "Nacionales" (30 enlaces), "Diarios de información económica" (tres enlaces), "Diarios de información deportiva" (cuatro enlaces) y "Prensa Internacional" (70 enlaces). La cantidad de información ofrecida y su clasificación — que facilita encontrar lo que se quiere buscar u orienta al curioso sin abrumarle - son dignas de destacar.

3. Revistas: Se ofrece la posibilidad de acceder a 50 revistas electrónicas de temática especializada (agricultura, cine, economía, etc.) y general.

4. Boletines oficiales: La información se presenta estructurada en seis categorías temáticas: "Unión europea" (tres enlaces), "España" (ocho a boletines oficiales y uno al diario de sesiones del Congreso), "Comunidades Autónomas", "Provincias", "Boletines de ofertas de empleo MAP" que cuenta con enlaces a "Ofertas de empleo público" y al "Boletín de premios, becas, ayudas y subvenciones"-, y "Boletines variados", que ofrece dos directorios web de boletines.

5. Libros: Ofrece dos enlaces a webs de libros electrónicos. Temáticamente, está recogida parte de la poesía española, las obras completas de Cervantes, novelas de autores extranjeros y textos sobre literatura.

6. Otros temas de interés: Este apartado presenta los webs clasificados por las diversas parcelas del conocimiento humano siguiendo la clasificación de la CDU. Además, encontramos un apartado correspondiente a información local y regional que enlaza con recursos digitales seleccionados sobre estos temas. Creemos, no obstante, que este recurso tan importante debería aparecer en la web inicial del sistema. Se trata, en definitiva, de un estupendo trabajo de diseño y configuración de recursos de información web. La trascendencia del recurso merecería otro título como "webs recomendadas", "Vademécum de webs", u otros similares. Es muy importante que al ver una web se sepa qué es lo que ofrece de un solo vistazo.

El quinto grupo temático se denomina Recursos de interés bibliotecario. Al igual que el anterior grupo, la página viene encabezada por un índice temático con enlaces internos que indican su contenido y acceder a sus cuatro apartados:

1. Direcciones generales de interés: Desde aquí se accede a las bases de datos del Ministerio de Educación y Cultura (Rebeca, Teseo, ISBN, etc.), el servicio de información en la Red CSIC, la Universidad de Murcia, el MAP, el Centro de Documentación Europea, y las revistas Correo Bibliotecario, Anales de Documentación y ANABAD.

2. Otras bibliotecas: Desde este apartado se accede a los SIW de la Biblioteca Nacional, Biblioteca Regional de Murcia, Biblioteca de la Universidad de Murcia, y de otras bibliotecas españolas y del mundo. 
3. Editores y libreros: Se accede desde este apartado a la Federación de Editores, y a "Recursos sobre librerías" de la Biblioteca Nacional.

4. Recursos de Internet: Facilita el acceso a 15 portales y buscadores internacionales, 23 en castellano, 8 metabuscadores, cinco servicios de correo gratuito, servicios de software gratis, 3 traductores de páginas web y 3 servicios de mensajería entre teléfonos móviles.

El sexto grupo temático se denomina Guías y novedades. Se ofrecen aquí guías de lectura y novedades. Cada guía y cada lista de novedades tiene un vínculo bajo el título VER para poder acceder a ellas. El séptimo grupo temático es el de Bibliopeque. Al igual que en la sede física de la biblioteca, en la virtual, también existe un espacio independiente para los niños. El diseño del sitio web es igual al comentado en "Otros temas de interés" del grupo temático biblioteca virtual. Es un diseño muy amigable que, en este caso, presenta diez cuadros con imágenes y texto de estilo desenfadado (letra Comic Sans MS y dibujos de objetos en lugar de fotografías). Se explican los servicios básicos de la sección infantil, cómo está organizado el fondo y cómo se accede a él. La intención es formativa e informativa, aunque no se puede interactuar con el sistema. No obstante, es destacable la información relativa a los tejuelos (qué son, para qué sirven, qué indican etc.).

El acierto del SIW de la biblioteca pública de Cieza consiste en agrupar los servicios, de tal manera que se facilita la rápida asimilación por parte del usuario de lo que se ofrece, es decir, el recurso de información potencialmente muestra toda su eficacia (capacidad de obrar). Ahora bien, si no se agrupan los servicios con coherencia, se consigue el efecto contrario, el potencial de eficacia se pierde, pues no se halla el servicio donde se necesita o se encuentra donde se prescinde de él. Como comentario final, se ha de decir que, a parte de que en todos los sitios web del sistema es posible enlazar al web principal, el SIW de la biblioteca municipal de Cieza es un modelo a seguir en cuanto a presentación, diseño y organización de recursos informativos. Es un SIW funcional, concebido únicamente como herramienta de información, es decir, no es un escaparate de la biblioteca sino la biblioteca misma en formato virtual. Podrá, en el futuro, ofrecerse más cantidad de información, más recursos, más enlaces a otros recursos y otras fuentes, aunque la distribución temática de los servicios nos parece completa y eficaz. Si acaso,convendría que el recurso de información local fuera accesible desde la web principal.

\section{2. EI SIW de la Biblioteca Pública Municipal de Jumilla}

El SIW de la biblioteca pública municipal de Jumilla —http://www.um.es/ $\sim$ gtiweb/pjumilla/principal.htm — se enmarca dentro del denominado Proyecto Jumilla — http://www. um. es/ gtiweb/pjumilla/pjumilla. htm—, el cual surge en el marco de colaboración establecido entre el Ayuntamiento de Jumilla y la Universidad de Murcia. Dicho proyecto pretende el desarrollo de sistemas de infor-

Scire. $8: 2$ (jul.-dic. 2002) 91-116. 
mación electrónica en el entorno de la biblioteca pública municipal de Jumilla, contribuyendo al acercamiento de este tipo de instituciones a la Sociedad de la Información. Precisamente, el primer cometido llevado a cabo ha sido la puesta en marcha y desarrollo del SIW de la biblioteca municipal.

La web principal del sistema nos ofrece la información dividida en dos partes principales: un grupo de informaciones incluidas en un recuadro a modo de "tablón de anuncios", y un segundo grupo de información a modo de menú en el que se indican las informaciones a las que se puede acceder directamente mediante sus enlaces correspondientes. Este menú informativo aparece en todos y cada uno de los sitios web que conforman el SIW de la biblioteca. Asimismo, en la web principal se indica siempre la fecha en la que se realiza la consulta o visita e incluye tres enlaces directos más: al Grupo de Investigación de Tecnologías de la Información de la Universidad de Murcia—que asesora y ofrece información y apoyo tecnológico para el desarrollo del web-, al certificado de calidad asignado al web, aspecto éste muy interesante pues viene a confirmar la realización de un buen trabajo, y al contador de visitas Nedstat que proporciona información estadística de las visitas realizadas al SIW. En el recuadro central presentado a modo de "tablón de anuncios" encontramos fotografías de Jumilla y su biblioteca, de la última web semanal recomendada y del cartel informativo del concurso literario "Ciudad de Jumilla". Las fotografías de Jumilla y la biblioteca no son sensibles, es decir, no incluyen enlace hipertextual, mientras que las otras fotografías sí son hipertextuales. Además, se proporciona acceso directo al catálogo de la biblioteca, a las bases del concurso literario, al recurso digital "FELIX" (fuentes de información electrónica) proporcionado por la Biblioteca Regional de Murcia - al que nos referiremos con más profundidad cuando analicemos el SIW de esta institución-, y a la biblioteca digital "Miguel de Cervantes" — http://www. cervantesvirtual.com/y, más concretamente, a la edición sonora de El Quijote. Este servicio recibe el nombre de "biblioteca de voces" y en él, a parte de proporcionar acceso directo a la biblioteca digital "Miguel de Cervantes" y sus patrocinadores y creadores (la Universidad de Alicante y el Banco Santander Central Hispano), se facilita un enlace de acceso directo para conseguir gratuitamente el software necesario para la audición de la obra. Por su parte, desde el menú informativo inferior es posible acceder directamente a varios servicios: información general, colección, actividades, reseñas, web de la semana, buscar en Internet, Proyecto Jumilla y contacto.

El servicio Información general se estructura en tres secciones principales: Datos generales, Instalaciones y Propuesta de reglamento. Estas secciones aparecen en forma de listado al comienzo del web permitiendo el acceso directo a las mismas mediante sus correspondientes enlaces internos. El apartado de datos generales incluye una fotografía que ofrece una vista exterior de la biblioteca y proporciona información de la misma: año de creación, localización y dirección postal,

Scire. $8: 2$ (jul.-dic. 2002) 91-116. 
personal de la biblioteca, colaboraciones con el museo municipal (incluyendo enlace directo al mismo) y con la Universidad de Murcia (incluyendo enlaces directos al Grupo de Investigación de Tecnologías de la Información y al Proyecto Jumilla). El apartado de instalaciones proporciona más información específica sobre la localización de la biblioteca ofreciendo, incluso, un plano de la localidad, que se puede descargar ampliado. La sección se completa con información concreta sobre las salas de lectura y consulta de la biblioteca (se incluyen fotografías de cada una de ellas). En cuanto a la propuesta de reglamento, incluye información suficiente sobre las condiciones que rigen el funcionamiento diario de la biblioteca.

La sección correspondiente a Colección ofrece información correspondiente al fondo documental existente en la biblioteca y las posibilidades de acceso al mismo a través del catálogo. En el momento actual la biblioteca se encuentra aún pendiente de ofrecer en línea la totalidad de sus fondos documentales. Esta posibilidad se conseguirá cuando se desarrolle plenamente el Proyecto CATA auspiciado por la Biblioteca Regional de Murcia y al que nos referiremos más adelante. Este sitio se estructura en "descripción general de la colección de fondos", "acceso a nuestro catálogo", "acceso al catálogo de la Biblioteca Regional” y "acceso al catálogo de la Universidad de Murcia". Al igual que en el caso anterior, el contenido se ofrecen en forma de lista de enlaces internos y a los distintos catálogos mencionados.

El apartado de Actividades proporciona información cultural referente a convocatorias, noticias relacionadas con Jumilla, premios literarios y exposiciones y actividades. Al igual que en los casos anteriores, la información se presenta mediante un índice basado en enlaces internos y ofrece acceso directo a las bases del premio literario, a las exposiciones, etc. La sección de Reseñas recoge comentarios y reseñas de publicaciones vinculadas a la ciudad de Jumilla, de manera que este recurso sirva como canal de difusión de parte de la actividad cultural editorial jumillana. Presenta la información bibliográfica estructurada en una lista de temas que ofrece enlaces internos al contenido. La reseña del documento descrito viene acompañada por su imagen digitalizada.

El apartado web de la semana recoge, a modo de histórico, las webs que han ido seleccionando en la web principal. Todas ellas son recursos de Internet relacionados con la cultura española. El conjunto de webs seleccionados se refieren a actividades culturales y se presentan en una tabla informativa en la que se ofrece información relativa a la fecha de celebración, el título de la misma y una imagen pulsable. Resulta ser, en consecuencia, un estupendo instrumento didáctico, formativo, informativo y educativo que proporciona la posibilidad de acceder a informaciones complementarias de interés para usuarios interesados.

El recurso Buscar en Internet es, ante todo, una herramienta útil y sencilla que facilita enormemente la tarea de buscar información por entre la inmensidad 
de Internet. La información que ofrece este recurso se basa en las enormes posibilidades que presenta, a la hora de la búsqueda de información en Internet, el buscador Altavista — http://www.altavista.digital.com-, uno de los más usados y conocidos por su eficacia y efectividad, así como por la cantidad de información que incorpora. La información que facilita esta sección del web es un resumen de la ayuda de este motor de búsqueda.

El servicio Proyecto Jumilla informa de las principales características de este proyecto de trabajo elaborado conjuntamente entre la Universidad de Murcia, a través del grupo de Investigación de Tecnologías de la Información, y el Ayuntamiento de Jumilla. Este sitio web proporciona acceso a toda la información concerniente al proyecto a través de una serie de enlaces de acceso directo, así como a recursos de información complementarios y de interés para el usuario. Los recursos principales a los que remiten dichos enlaces son: "Descripción general del proyecto", "La ciudad de Jumilla. Una breve historia", "el museo municipal Jerónimo Molina", "Cultura y sociedad de la información", y otros sitios web de interés como "Semana Santa de Jumilla", "Consejo Regulador de la Denominación de Origen Jumilla", "Ayuntamiento de Jumilla” y "Universidad de Murcia". Asimismo, ofrece acceso directo al web de la biblioteca.

De entre los apartados o secciones existentes, la más importante, sin lugar a dudas, es la referente a Descripción del proyecto, la cual, ofrece todos los datos y enlaces de interés para su comprensión. Así, se informa de los preliminares que sirven de base para la puesta en marcha del proyecto, de las condiciones y cláusulas que rigen el convenido de colaboración entre la Universidad de Murcia y el Ayuntamiento de Jumilla con respecto a este proyecto, de las líneas básicas de actuación del mismo entendiendo al Proyecto Jumilla como una herramienta para el desarrollo de un sistema integrado de información local —http: //fesabid98.florida-uni.es/Comunicaciones/jl_gonzalez/jl_gonzalez. htm- (8), y de la primera actuación para su desarrollo, llevada a cabo hasta el momento, que es la creación del SIW de la biblioteca municipal. El resto de enlaces principales y complementarios facilitan información referida a la historia de la localidad, el museo municipal, a aspectos sobre la Sociedad de la Información mediante una serie de documentos de interés para la promoción de la Cultura por medio del desarrollo de sistemas de información electrónica, mostrando los aspectos positivos que en este campo puede tener la implantación de la Sociedad de la Información, y enlaces directos al web sobre la Semana Santa jumillana y su Ayuntamiento, así como a la Universidad de Murcia. Por último, el recurso Contacte permite ponerse en contacto con los responsables de la biblioteca para efectuar cualquier tipo de consulta, sugerencia, queja u opinión a través de correo ordinario, por teléfono o correo electrónico.

En definitiva, nos encontramos ante un web joven y por desarrollar plenamente, con grandes posibilidades informativas y culturales, con un diseño ame-

Scire. $8: 2$ (jul.-dic. 2002) 91-116. 
no y agradable, sin sobrecarga de imágenes (tiene las justas y necesarias y no de gran tamaño) que, integrado en un proyecto de trabajo más amplio y ambicioso, puede llegar a cumplir una función realmente importante desde la perspectiva bibliotecaria, informativa y comunicativa, lo que le hará convertirse en un referente necesario para sus usuarios.

\section{3. EI SIW de la Biblioteca Regional de Murcia}

La Biblioteca Regional de Murcia se configura como la biblioteca central de la Región de Murcia, cabecera de la Red de bibliotecas públicas, y nexo de unión entre ellas y el Sistema Bibliotecario Español. Entre las funciones que tiene encomendadas destacan las de recopilar, conservar y difundir el patrimonio bibliográfico, sonoro y visual de la Comunidad o que haga referencia a ella, y el fomento y promoción de donaciones, legados y depósitos de bibliotecas de autores, intelectuales o instituciones murcianas a favor de la Biblioteca Regional.

De entre los diversos proyectos de trabajo que desarrolla, nos interesamos aquí por el denominado "Proyecto web de la Biblioteca Regional", el cual, se encuentra integrado dentro de las actividades del servicio de referencia y consulta de la biblioteca para proveer a esta institución de servicios avanzados basados en la explotación de las tecnologías de la información y comunicación. El SIW de la Biblioteca Regional de Murcia — http://www.bibliotecaregional.carm.es- presenta la información a modo de "portal bibliotecario" (9), estructura ésta de reciente aplicación en diferentes y diversos servicios y recursos web. A primera vista, el diseño de la web inicial o principal del sistema resulta atractivo y amigable con una gran cantidad de información que permite resaltar los aspectos y recursos informativos principales que ofrece al usuario. Sin embargo, la disposición y presentación de la información, un tanto "aglomerada", puede producir en el usuario una opinión negativa al verse un tanto desbordado, debido a la gran cantidad de información que se ofrece en tan poco espaci. Incluso en algunos casos se repiten los mismos recursos de información distribuidos en distintos lugares del web inicial (aunque esto también tiene su punto de vista positivo pues es posible llegar y/o localizar una determinada información desde diversos lugares del web). Asimismo, la existencia de muchas imágenes puede ocasionar cierto retardo a la hora de cargarse la información inicial del sistema.

Esta presentación de la información a modo de portal es una especie de puerta de entrada al sitio web de la biblioteca, como si de un lugar de acogida para el usuario se tratase. Dentro de este portal podemos distinguir varias parcelas o grupos de información. En primer lugar, una zona a modo de "titular periodístico" o encabezamiento donde aparecen varias imágenes acompañadas por textos informativos referidas a diversos recursos de información que ofrece el sistema. Desde allí, a través de los enlaces correspondientes, podemos acudir a la información 
referente a la renovación de los préstamos en línea, a las actividades de animación a la lectura y a su publicación actualBIBLIOTECA. En segundo lugar, una zona de menú informativo desde donde puede accederse a la agenda de actividades de la biblioteca y a los principales recursos informativos del sistema: "guía fácil", "información", "servicios" y "FELIX" (base de datos de fuentes de información electrónicas). En tercer lugar, una zona central bastante extensa que presenta varios directorios: en la parte izquierda, "búsqueda y catálogos", que ofrece acceso a los distintos recursos disponibles para la búsqueda y recuperación de información (catálogo de la biblioteca con sus distintas variantes, catálogo colectivo de las bibliotecas de Región de Murcia, FELIX y otros catálogos de otras bibliotecas disponibles en la Red); en la parte central, "servicios en línea", que proporciona acceso a determinados servicios en línea disponibles (renovación de préstamos, ayuda del web, un servicio de referencia cooperativo con otras bibliotecas públicas denominado "Pregunte, las bibliotecas responden", desideratas y préstamo interbibliotecario); en la parte derecha, "líneas de información" (facilita guías y propuestas de lectura), "información útil" sobre actividades y convocatorias literarias y culturales, y "unidades y secciones" existentes en la biblioteca. En cuarto lugar, una zona inferior donde se recogen recursos de acceso a distintas redes y sistemas bibliotecarios españoles, así como acceso a una herramienta de consulta e información denominada "Tu bibliotecario virtual" además de al recurso "Pregunte, las bibliotecas responden" y a la información referente a la campaña de animación a la lectura en los colegios para el presente curso escolar. También, y este es un recurso muy interesante, ofrece un enlace que permite consultar todos los contenidos del SIW de la biblioteca en idioma inglés. Asimismo, incorpora un contador de visitas. Por último y en quinto lugar, bajo la anterior parcela informativa, encontramos los datos básicos de la biblioteca: dirección postal, teléfono y fax de contacto, correo electrónico, URL del web de la biblioteca y dependencia administrativa dentro del organigrama de la Comunidad Autónoma de Murcia.

El estudio y análisis de este SIW merecería, por sí solo, un trabajo dedicado a él en exclusiva. Aún así, intentaremos analizar en las páginas de las que disponemos todos los aspectos más significativos, de manera que consigamos ofrecer sus principales características de manera clara, sintética y fácil de asimilar. Para empezar hemos de destacar que todos los sitios web que conforman el sistema, con la excepción de los apartados de animación a la lectura, presentan la posibilidad de acceder directamente a sus distintos recursos o secciones a través de varios menús de ventanas desplegables para facilitar la navegación del usuario por todo el web, retornar directamente al web inicial o principal mediante el enlace correspondiente, y acceder directamente al recurso digital "Tu bibliotecario virtual" (ayuda en línea para navegar por el web y explotar al máximo sus recursos). Los principales recursos, secciones y servicios a analizar se describen a continuación.

Scire. $8: 2$ (jul.-dic. 2002) 91-116. 
Mi biblioteca. Servicios personalizados en Internet permite renovar los préstamos, consultar cada usuario sus datos personales como socio de la biblioteca, suscribirse al servicio de difusión selectiva de información por medio del correo electrónico y, en el futuro, realizar reservas. Evidentemente, este servicio ofrece al usuario la posibilidad de realizar una serie de servicios que no precisan necesariamente de la presencia física del mismo en la biblioteca, lo cual, consigue redundar en el objetivo de acercar la biblioteca al usuario con independencia de su lugar de residencia. Presenta un enlace a la sección de bibliobuses y una pequeña fotografía sobre el interior de la biblioteca.

Sábados de animación a la lectura y Campaña de animación a la lectura para centros escolares son servicios dirigidos a los más jóvenes que pretenden la integración de este sector de la sociedad en el universo del libro y la lectura. En ambos casos, los sitios web presentan un diseño atractivo, con gran colorido, de manera que atraiga la atención precisamente de los más pequeños. Se proporciona información, imágenes, fotografías, etc., que enriquecen y complementan la información sobre las actividades a desarrollar.

ActualBiblioteca es la hoja informativa editada por la Biblioteca Regional, en la cual se recomiendan la lectura y consulta de distintas fuentes bibliográficas y no bibliográficas. Permite el acceso a todos los números publicados. Por su parte, Agenda ofrece el programa de actividades culturales, formativas e informativas que desarrollan la biblioteca $u$ otras bibliotecas o instituciones culturales y educativas durante el año.

Guía fácil de la biblioteca es, sin lugar a dudas, uno de los recursos más logrados en todo el web por su funcionalidad, hipertextualidad e interactividad. Esta guía de acceso o mapa del web permite que podamos movernos y navegar por todo el sistema sin perdernos en ningún momento. Nos encontramos, pues, ante una herramienta extraordinaria, fácil de usar y funcional que guía al usuario por todos los recursos e informaciones que conforman el sistema. La guía fácil de la biblioteca proporciona respuesta a cuatro preguntas básicas: “¿qué buscas?", “¿dónde está?”, “¿qué necesitas?” y “¿qué tienes?”. Para ello, ofrece la posibilidad de visualizar todos y cada uno de los recursos en una figura gráfica que ofrece respuestas a estas cuestiones fundamentales en la visita de todo SIW. Un recurso, pues, muy conseguido y totalmente recomendable.

Información es un servicio desarrollado por el servicio de información y referencia de la biblioteca cuyo objetivo es dar a conocer mejor cómo queda organizada la biblioteca y sus servicios para, de esta manera, poder sacar el máximo partido de todos los recursos informativos que ofrece al usuario. Así, se incide en la idea de que la biblioteca es un centro de información activo donde se puede encontrar mucho más de lo que se puede esperar. Este sitio web permite 
acceder, mediante enlaces de acceso directo, a una serie de recursos informativos que ofrece el sistema. Dichos recursos aparecen mostrados a modo de listado y agrupados temáticamente según la siguiente disposición: "conoce la biblioteca" -ActualBiblioteca, la biblioteca de la A a la Z, directorio y servicios de la biblioteca, la atención al usuario, cómo mantener nuestra biblioteca, normas de préstamo, datos estadísticos básicos, el edificio de la Biblioteca-, "cómo buscar y encontrar información" —ubicación de colecciones y servicios, catálogos de la biblioteca, clasificación temática, clasificación de la música, el cine por géneros, prensa digital, ayuda para buscar en el catálogo_-, "cómo hablar con nosotros" —Desideratas y Tu bibliotecario-y "documentos sobre bibliotecas" —Plan de Impulso de las Bibliotecas Públicas en España, Ley de bibliotecas y patrimonio bibliográfico de la Región de Murcia (1990), Reglamento de las Bibliotecas Públicas del Estado y del Sistema Español de Bibliotecas (Real Decreto 582/1989), Manifiesto de la UNESCO sobre bibliotecas públicas (1994) y Declaración de los derechos de las bibliotecas (ALA). Como se puede comprobar, el conjunto de recursos a los que se puede acceder desde este servicio es amplio y bastante completo, ya que no sólo se proporciona acceso a recursos sobre la propia biblioteca, a técnicas y métodos de búsqueda y recuperación de información y a facilitar la intercomunicación biblioteca-usuario, sino que también ofrece acceso a documentación e información de referencia básica para entender mejor la funcionalidad y cometidos de la biblioteca y de las bibliotecas.

Servicios informa de la gama de servicios ofrecidos por la biblioteca. Facilita el acceso a todos ellos mediante su enlace correspondiente. Asimismo, presenta información sobre el origen de la biblioteca, un directorio básico de servicios con teléfono y correo electrónico de cada uno de ellos, e información adicional sobre el edificio de la biblioteca acompañado de un reportaje del mismo que contiene toda la información relativa a la construcción y diseño del edificio y fotografías del mismo. Por tanto, desde este sitio web es posible conocer y saber qué servicios oferta la biblioteca y su acceso a los mismos a través de los enlaces de acceso existentes. Esta información también es accesible, desde la web inicial, a través del directorio "unidades y secciones".

Las unidades, secciones y servicios ofertados por la biblioteca son esencialmente los siguientes: Biblioteca Infantil y Juvenil, Hemeroteca, Fondo Regional, Mediateca, Red Multimedia, Actividades Culturales, Coordinación Bibliotecaria, Referencia y Consulta, y Editora Regional. De cada una de ellas se informa convenientemente de sus cometidos y objetivos. De hecho, se ofrecen al ciudadano como servicios personalizados de orientación. Describimos, a continuación, algunos de ellos que, por su interés y novedad, merecen nuestra atención.

El recurso Biblioteca Infantil y Juvenil es uno de los más interesantes. Utiliza un fondo con color muy llamativo y atractivo para los más pequeños e incluye

Scire. $8: 2$ (jul.-dic. 2002) 91-116. 
numerosa información concerniente a esta sección de la biblioteca, así como imágenes, dibujos y fotografías relacionadas con el asunto que trata. Asimismo, proporciona acceso directo a otros recursos de interés para los más jóvenes mediante enlaces directos (enlaces a los recursos antes comentados de animación a la lectura). También es posible acceder, a través de enlaces directos, a otros recursos como: "Tu rincón", espacio donde se les ofrece la oportunidad de compartir sus gustos con otros niños, encontrar sugerencias y lecturas recomendadas, etc.; lecturas recomendadas clasificadas por edades; "Minibibliotecario", recurso informativo que resuelve, por correo electrónico, las dudas que puedan tener sobre cualquier aspecto o servicio de la biblioteca; "Biblioteca para padres", desde el cual, se aconseja a los padres de los niños a la hora de iniciarles en la lectura; "Catálogo" que permite la consulta del conjunto de obras del fondo infantil y juvenil; y un apartado en el que se explica la función de la tarjeta de lector

El sitio web sobre la Hemeroteca Regional ofrece información sobre la misma e incluye enlaces de acceso directo al Boletín Oficial de la Región de Murcia (BORM), a la guía fácil de publicaciones seriadas de la biblioteca y al recurso "Prensa digital en Internet". Este recurso ofrece acceso directo a las versiones digitales de varios diarios regionales y nacionales, así como a "PRENSADIGITAL.com", sistema de búsqueda de noticias e informaciones que permite buscarn en la versión digital de los principales diarios españoles mediante palabras clave e intervalos de tiempo (hoy, ayer y hoy, la última semana, el último mes).

Por su parte, Mediateca informa de los fondos existentes sobre cine, vídeo y música. Para ello ofrece enlaces de acceso directo a cada una de estas tipologías documentales, sus respectivos catálogos, su disposición y localización física, etc. así como recomienda una selección sobre cada uno de ellos. Contiene también un enlace directo a Red Multimedia, apartado que presenta como aspecto más interesante el recurso "Talleres sobre el uso inteligente de Internet: programa de formación de usuarios en tecnologías de la información", desde el cual, se informa sobre estos talleres y sus características, requisitos, plazos y fechas de inscripción, etc. También permite descargar la documentación utilizada para dichos talleres.

El recurso sobre Coordinación Bibliotecaria indica qué hace este departamento de la biblioteca y cómo lo hace. Incluye dos enlaces de acceso directo a "Servicio de bibliobus" y "Proyectos", a saber, la Biblioteca Virtual "Pío Tejera", ABIMUR (automatización del servicio de bibliobus), MOUSE (Automatización de la Red de Bibliotecas de la Región de Murcia), CATALOGA (Catalogación masiva de la Biblioteca Regional) y FORMACIÓN (Formación de bibliotecarios municipales)

FELIX, por su parte, es una herramienta utilísima para la búsqueda y recuperación de información. FELIX se concibe como un motor de búsqueda de fuentes de información electrónica sobre diversas y distintas materias, ya sean gene-

Scire. $8: 2$ (jul.-dic. 2002) 91-116. 
rales o especializadas. FELIX permite la consulta de información en modo texto libre, así como realizar búsquedas avanzadas mediante el uso de conectores booleanos. Asimismo, el usuario también puede realizar la búsqueda directamente por cada uno de los temas presentados.

Guías de Lectura, es un recurso de información interesante y novedoso que pretende dar a conocer la obra literaria de un determinado escritor y, por extensión, fomentar la lectura. Basa su utilidad en el hecho de ofrecer una información exhaustiva y muy completa acerca de un determinado literato y su producción bibliográfica. Desde datos biográficos hasta breves fragmentos de obras destacadas del autor tienen cabida en este espacio digital del web que se ve completado por valiosísima información complementaria sobre el autor y su obra: si existe alguna versión cinematográfica de alguna sus obras, artículos periodísticos sobre el autor y su obra literaria, información sobre el autor en Internet, etc.

Búsqueda y catálogos permite visualizar en línea los diferentes catálogos existentes en la biblioteca, así como en el recurso "FELIX", al cual ya nos hemos referido. La búsqueda puede realizarse en el catálogo general o bien en los diferentes catálogos existentes por materias. Asimismo, permite acceder también a los catálogos en línea de otras bibliotecas: Universidad de Murcia, Bibliotecas Públicas del Estado, Biblioteca Nacional, etc., todos los cuales permiten realizar búsquedas simultáneas cuando pertenecen a más de una biblioteca). Por su parte, el catálogo en línea contiene también el catálogo colectivo de las bibliotecas municipales de la Región de Murcia y permite acceder a cada una de ellas por separado. Permite la búsqueda por autor, título, materias, editorial, año de publicación y texto libre, así como reiniciar la búsqueda de información tantas veces como se quiera a través de un enlace de acceso directo.

Servicios en línea es un conjunto de servicios que ofrece la biblioteca exclusivamente a través de Internet. Dichos servicios son: Mi biblioteca (ya comentado al principio), Tu bibliotecario virtual, Pregunte, las bibliotecas responden, Desideratas y Préstamo interbibliotecario. Tu bibliotecario virtual es un servicio de atención y orientación en línea que ofrece la biblioteca a sus usuarios no presenciales. Desde este recurso, que actúa como guía día y ayuda en línea, se orienta al usuario a la hora de navegar a través de todo el web de la biblioteca, al tiempo que sirve de apoyo a la hora de desvelar cualquier duda que tenga el usuario durante la visita del web: cómo moverse por entre los diferentes sitios web del sistema, cómo localizar una determinada información, cómo usar los servicios de la biblioteca, etc. Para ello, se ofrece al usuario la posibilidad de que formule su consulta, queja o reclamación sobre algún servicio, sección o recurso informativo concreto en una ventana de diálogo. Asimismo, también proporciona otro recuadro desde el cual el usuario da a conocer algunos datos personales para que la biblioteca se ponga en contacto con él lo antes posible (en especial, una cuenta de

Scire. $8: 2$ (jul.-dic. 2002) 91-116. 
correo electrónico). Asimismo, se indica que si la consulta requiere una búsqueda documental concreta, el usuario deberá dirigirse a otro servicio también en línea: Pregunte, las bibliotecas responden es un servicio bibliotecario de atención de consultas y peticiones de información en línea ofrecido por el Ministerio de Educación, Cultura y Deportes. El web de este recurso bibliotecario ofrece información general sobre este servicio y sobre la posibilidad de proporcionar servicios personalizados a usuarios con necesidades de información muy puntuales, indica qué bibliotecas participan en la prestación cooperativa de este servicio,e incluye un buscador de las preguntas realizadas por otros usuarios así como de las respuestas ofrecidas. Además, si hubiera dudas sobre el funcionamiento del servicio y cómo interrogar al sistema sobre una consulta concreta, ofrece la posibilidad de solventarlas a través de una serie de datos complementarios. Estamos, en definitiva, ante un servicio de información muy útil y práctico, de carácter cooperativo entre varias bibliotecas — entre ellas la Biblioteca Regional de Murcia- y del que pueden sacar provecho usuarios con intereses distintos con independencia de su lugar de residencia. Por fin, Desideratas servicio en línea de la biblioteca que permite que el usuario le haga saber sobre qué libros, vídeos, revistas, películas, música, etc., debería adquirir. Para ello, ofrece un tipo de formulario en pantalla en el cual el usuario debe indicar el título de la obra, su autor (si lo conoce) y el tipo documental. Además, el usuario tiene un apartado donde puede dar a conocer los comentarios que crea oportunos sobre las sugerencias para adquirir, así como dejar sus datos personales, sobre todo una dirección de correo electrónico, para ser avisado en cuanto dicha petición se encuentre en la biblioteca. Como podemos observar, tanto en este caso como en el servicio "Tu bibliotecario virtual", la biblioteca ofrece al usuario la posibilidad de informarle acerca de sus peticiones especialmente por correo electrónico, una herramienta de comunicación cada vez más habitual y corriente en nuestra actividad diaria

Por último, Préstamo interbibliotecario es un servicio en línea que ofrece la biblioteca para conseguir una determinada obra en préstamo desde otra biblioteca. Se informa al usuario de las condiciones y requisitos para llevar a cabo este préstamo y se le ofrece en línea un formulario de peticiones, así como el acceso directo a una serie de bibliotecas con presencia en la Red. En este formulario el usuario deberá indicar si quiere la obra en préstamo o una reproducción de la misma. Igualmente debe indicar algunos datos de dicha obra (si nos lo conoce todos) $\mathrm{y}$, nuevamente, unos datos personales, en especial una cuenta de correo electrónico, para avisarle cuando esté disponible esa obra. Como hemos podido comprobar, estos servicios en línea ofrecen una gran interactividad y permiten mantener una relación intercomunicativa estrecha con el usuario, lo cual redunda en la calidad del servicio ofrecido al usuario no presencial de la biblioteca.

Finalmente, Redes de bibliotecas ofrece enlaces a los siguientes recursos:

Scire. $8: 2$ (jul.-dic. 2002) 91-116. 
1. Bibliobuses Regionales informa de qué son los bibliobuses, y de su función, rutas y horarios. Tiene una ventana de búsqueda, desde la cual, es posible consultar cuando pasa el bibliobús por una determinada localidad. También permite acceso al catálogo de "obras en ruta". En el momento del estudio, existía una cierta falta de actualización en la presentación.

2. Bibliotecas Públicas de la Región de Murcia presenta tres tipos de información y se constituye como un recurso de información para la Red Regional de las Bibliotecas Públicas. El primer tipo de información presenta, a modo de directorio, las bibliotecas públicas de la Región de Murcia y sus datos estadísticos de los dos últimos años. El segundo tipo ofrece enlaces de acceso directo a los SIWs de las bibliotecas municipales de la región (Cieza y Jumilla). El último tipo de información, el más interesante, presenta recursos aprovechables para los profesionales de las bibliotecas de la Región: un manual de procedimientos para la catalogación automatizada, publicaciones, cursos de formación, etc.

3. Enlaces a las Bibliotecas Públicas del Estado, Red de Bibiliotecas REBIUN y Red de Bibliotecas del CSIC (CIRBIC).

Como colofón, hemos de comentar que este SIW es, además de un recurso de información para el usuario, un herramienta de trabajo útil para el profesional de la biblioteca. Este "portal bibliotecario", como ya se apuntó al principio, presenta cierta aglomeración de datos en el web principal, cosa que puede retraer al usuario neófito. No obstante, con su uso y familiarización, esta pequeña confusión inicial desaparece.

\subsection{Tablas comparativas de los SIW estudiados}

Para realizar este análisis comparativo hemos considerado oportuno utilizar una estructura tipo de SIW bibliotecario basada en cuatro niveles: el nivel de evaluación de calidad del sistema y otros tres niveles de evaluación, a saber, el nivel de información general, donde se recogen datos institucionales útiles para el acceso físico a la biblioteca y relacionados con la política bibliotecaria, el nivel de información de colección y servicios y el nivel de información sobre servicios añadidos y/o avanzados.

Según se desprende de la tabla I, los tres SIWs ocupan como máximo el tamaño de la pantalla desde donde se visualiza la información, sin necesidad de que el usuario tenga que desplazarse horizontalmente para acceder a sus contenidos. Igualmente, el nivel de intearctividad de estos sistemas web con el usuario es óptimo ya que ofrece diversas opciones para mantener contacto directo e intercomunicativo con el mismo. Sin embargo, en ninguno de los casos estudiados se ofrece información de las necesidades y limitaciones tecnológicas del sistema

Scire. $8: 2$ (jul.-dic. 2002) 91-116. 
(téngase en cuneta que no todos los usuarios de Internet cuentan con la misma tecnología para acceder a las informaciones de la Red), ni aclaran ni definen qué navegador debe utilizarse para una visualización correcta del web (no es ningún secreto que no todos los navegadores de Internet permiten visualizar idénticamente los contenidos, diseños o estructuras de los mismos sitios web).

Por otra parte, en el capítulo de diseño de los SIWs, hay que decir que todas las imágenes que ofrecen o, al menos, una gran mayoría, presentan textos explicativos de las mismas y sirven para complementar la información textual existente. En este sentido, la Biblioteca Regional es la que ofrece un gran número de imágenes en su web inicial o principal, frente a los SIWs de las bibliotecas municipales de Cieza y Jumilla que usan muy pocas y de pequeño tamaño, lo cual puede ocasionar algún retardo a la hora de cargarse la información inicial del sistema. No obstante, todos los SIWs ofrecen de cara al usuario un diseño homogéneo por todo el web de manera que usuario encuentre fácil y atractiva la visita, así como por el hecho de hay un buen contraste entre la información textual propor-

\begin{tabular}{|c|c|c|c|}
\hline Criterios & Biblioteca Regional & Biblioteca Cieza & Biblioteca Jumilla \\
\hline Contenido horizontal & Sí & Sí & Sí \\
\hline Limitaciones tecnológicas & No & No & No \\
\hline Navegadoridóneo & No & No & No \\
\hline Interactividad & Sí & Sí & Sí \\
\hline Imágenes con texto & Sí & Sí & Sí \\
\hline Cantidad imágenes en Web inicial & Muchas & Pocas & Pocas \\
\hline Contraste texto/fondo & Bueno & Muy bueno & Muy bueno \\
\hline Diseño homogéneo & Sí & Sí & Sí \\
\hline Mapa del Web & Sí & No & No \\
\hline Textos claros y breves & Casi siempre & Siempre & Siempre \\
\hline Menús de vínculos & Sí & Sí & Sí \\
\hline Enlaces Web inicial & Sí & Sí & Sí \\
\hline Autoría SIW & No & No & No \\
\hline Fecha actualización & No & No & Sí \\
\hline E-Mail/Contacto & Sí & Sí & Sí \\
\hline URL en Web inicial & Sí & Sí & Sí \\
\hline Logotipo & Sí & No & No \\
\hline Web otros idiomas & Sí & No & No \\
\hline Ayuda en línea para el uso de los recursos & Sí & Sí & Sí \\
\hline URL nemotécnica & Sí & No & No \\
\hline Rapidez acceso SIW & Sí & Sí & Sí \\
\hline Reconocimientos & No & No & Sí \\
\hline
\end{tabular}


cionada y el color de fondo ofrecido, textos que en su mayoría, salvo ciertas excepciones en el SIW de la Biblioteca Regional, suelen ser breves y bastante claros. Otra cuestión en su diseño en la que aciertan de lleno los tres SIWs estudiados es el uso de menús de vínculos, lo cual favorece y facilita la navegación

\begin{tabular}{|c|c|c|c|}
\hline Criterios & Biblioteca Regional & Biblioteca Cieza & Biblioteca Jumilla \\
\hline $\begin{array}{l}\text { Mapa geográfico de la localidad y } \\
\text { localización de la bibl ioteca }\end{array}$ & No & Sí & Sí \\
\hline Horarios & Sí & Sí & Sí \\
\hline Servicios & Sí & Sí & Sí \\
\hline Datos contado & Sí & Sí & Sí \\
\hline Reglamento & Sí & Sí & Sí \\
\hline Historia biblioteca & Sí & Sí & Sí \\
\hline
\end{tabular}

Tabla II. Nivel de información general

\begin{tabular}{l|c|c|c}
\hline Criterios & \multicolumn{1}{c}{ Biblioteca Regional } & \multicolumn{1}{c}{ Biblioteca Cieza } & Biblioteca Jumilla \\
\hline Novedades bibliográficas e informativas & Sí & Sí & No \\
\hline Detalles fondo documental & Sí & Sí & Sí \\
\hline Catálogos & Sí Sí & Sí \\
\hline OPAC & Sí & Sí & Sí \\
\hline Enlaces a otros OPACs & Sí & Sí & No \\
\hline Colecciones digitales & Sí & Sí & Sí \\
\hline Servicios en línea & Sí & Sí & Sí \\
\hline Buscadores & Sí & Sí & Sí \\
\hline Formularios y desideratas & Sí & Sí & No \\
\hline Hemeroteca digital & Sí & Sí & No \\
\hline Guías de lectura & Sí & Sí & Sí \\
\hline Información Local & No & Sí & Sí \\
\hline Formación de usuarios & Sí & Sí & Sí \\
\hline Información sobre Actividades Culturales & Sí & No &
\end{tabular}

Tabla III. Nivel de información de colección y servicios

\begin{tabular}{l|cc|c}
\hline Criterios & \multicolumn{1}{c}{ Biblioteca Regional } & Biblioteca Cieza & Biblioteca Jumilla \\
\hline $\begin{array}{l}\text { Colecciones de vínculos/enlaces a Webs } \\
\text { temáticos }\end{array}$ & Sí & Sí & Sí \\
\hline Enlaces con otros centros culturales & Sí & Sí & Sí \\
\hline Exposiciones virtuales & No & No & Sí \\
\hline Estadísticas uso/Contador visitas & Sí & No & Sí \\
\hline Acceso a servicios añ adidos de Internet & Sí & Sí & Sí \\
\hline Servicios cooperativos en línea & Sí & Sí & Sí \\
\hline
\end{tabular}

Tabla IV. Nivel de información sobre servicios añadidos y avanzados 
estructural, así como el hecho de que presenten siempre enlaces directos para regresar al web inicial del sistema.

Sin embargo, con las visitas realizadas a los tres SIWs no hemos podido comprobar quién es autor personal o institucional de la construcción y mantenimiento del sistema. Incluso, una cuestión tan esencial como es en Internet saber la fecha de la última actualización de la información tan sólo aparece claramente expresada en el de la biblioteca municipal de Jumilla. No obstante, sí ofrecen mecanismos de comunicación biblioteca/usuario, bien por medio de dirección de correo electrónico, bien mediante buzones de sugerencias, etc. También en todos los SIWs se refleja la URL del sitio en el web inicial del mismo, aunque tan sólo en el caso de la Biblioteca Regional su SIW se presenta un logotipo de reconocimiento institucional. Además, este SIW es el único de los tres analizados que permite visualizar sus contenidos en otros idiomas, concretamente en inglés. Por último, indicar que los tres SIWs proporcionan al usuario ayudas en líneas o explicaciones complementarias para el uso de recursos de búsqueda y recuperación de información — catálogos, bases de datos, etc.— además de ofrecer un rápido acceso a los contenidos informativos existentes en todo el sistema. Mientras, tan sólo el SIW de la Biblioteca Regional presenta una URL nemotécnica, esto es, fácilmente recordable para el usuario, y es el SIW de la biblioteca municipal de Jumilla el único que indica con claridad que ha sido merecedor de un reconocimiento o recomendación de calidad.

Todos los SIWs ofrecen una cantidad de información de tipo institucional o básica bastante extensa y aceptable por lo que, desde este aspecto, no hay nada que objetar. Sus informaciones son claras y completas. Asimismo, desde la perspectiva de la información acerca de sus colecciones, cómo consultarlas y los servicios ofrecidos. El nivel de calidad también es bastante similar en los tres SIWs con ciertas excepciones muy puntuales que, no obstante, deben ser tomadas en consideración por parte de sus responsables: por ejemplo, la Biblioteca Regional no ofrece en su SIW información regional, mientras que las bibliotecas de Cieza y Jumilla sí ofrecen información local o, al menos, recursos de información local. En cuanto a los servicios añadidos o avanzados ofrecidos, sus prestaciones son bastantes similares, quizás el SIW de la biblioteca municipal de Cieza, en este sentido, muestre mejores y más posibilidades, aunque por lo general pueden considerarse bastante logrados los SIWs de las tres bibliotecas en este capítulo.

\section{Conclusiones}

La situación actual de las bibliotecas públicas de la Región de Murcia, en cuanto al desarrollo e implantación de SIW, es aún pobre en relación con otras Comunidades Autónomas, ya que son tan sólo tres bibliotecas, la Biblioteca Regional de Murcia y las bibliotecas públicas municipales de Cieza y Jumilla, las

Scire. $8: 2$ (jul.-dic. 2002) 91-116. 
que tienen desarrollados estos servicios virtuales y/o digitales. Estos webs son todavía jóvenes, pero ya ofrecen una gama de servicios amplia e interesante. Tenemos constancia, asimismo, de que existen proyectos de trabajo en marcha para desarrollar estos servicios de información web en otras bibliotecas públicas municipales de la Región, como es el caso de las bibliotecas municipales de Torre Pacheco, Los Alcázares, Lorca, Puerto Lumbreras, etc., lo que hace presagiar una mejora de la situación en un futuro a corto o medio plazo. Los SIW en las bibliotecas públicas murcianas, tal y como se aprecia en la comparativa realizada, cumplen en la mayoría de los casos, con los principales criterios de satisfacción y calidad que se aplican, por término general, en la evaluación de cualesquiera recursos digitales (10). Estas bibliotecas se enmarcan, pues, dentro de los preceptos que definen a la nueva "biblioteca sin paredes", la biblioteca virtual que ofrece servicios, informaciones, recursos y prestaciones, tanto a usuarios presenciales como no presenciales, desde la perspectiva de la eficacia, usabilidad y accesibilidad de los mismos. Igualmente, sería muy interesante mantener este estudio al día y actualizarlo periódicamente, de manera que se confirme y complete así esta evolución positiva y necesaria de los servicios bibliotecarios de la Región de Murcia.

\section{Notas}

(1) Hay que hacer constar que no existe unanimidad para referirse al concepto de biblioteca digital. Existen numerosas denominaciones como biblioteca electrónica (Amat 1990), biblioteca digital (Pérez Alarcón, 1999), biblioteca virtual (Agustín 1998), biblioteca híbrida (Hípola, Vargas-Quesada y Senso, 2000) o, incluso, biblioteca universal que intentan describir una misma realidad: un entorno donde documentos, servicios, recursos y personal se integran entre sí favoreciendo los flujos de elaboración, diseminación, utilización y almacenamiento de información para la generación de conocimiento. Una síntesis terminológica, con todas las denominaciones al uso, puede consultarse en http://gtil.edu.um.es:8080/jgomez/bibesp/temal-BibDigitales.htm.

(2) Si echamos un vistazo a la situación de las Bibliotecas Públicas del Estado en cuanto a su situación y su presencia en la Red Internet, podemos constatar que no todas tienen una presencia uniforme en la Red, ni proporcionan la misma cantidad ni calidad de información. Si consultamos la dirección web que el Ministerio de Educación y Cultura ofrece para informar de las Bibliotecas Públicas del Estado — http:// www.mcu.es/bpe/info.html— es posible llegar a una primera conclusión: no todas estas bibliotecas ofrecen un Sistema web de Información sobre ellas mismas, pues en la gran mayoría de los casos tan sólo ofrecen la posibilidad de consultar los fondos existentes a través de los distintos catálogos en línea. Tan sólo un número reducido de estas bibliotecas permite realizar una visita pormenorizada a sus recursos de información y documentación. De entre estas bibliotecas se puede destacar la calidad de sus Sistemas de Información en los casos de la bibliotecas públicas de Tarragona —http:// www.biblio.fut.es/—, Valladolid —http://bpval.bcl.jcyl. es/—o de Logroño —http:// biblioteca.larioja.org - , entre otras. En cuanto a las bibliotecas públicas municipales,

Scire. $8: 2$ (jul.-dic. 2002) 91-116. 
éstas también deben hacer suya esta nueva herramienta de trabajo y servicio. Sería paradójico que después de tantos años, décadas, incluso siglos, defendiendo la necesidad y el derecho de acceso a la información, la educación, la cultura y la lectura para todos por igual, resultara que las bibliotecas públicas municipales, las más cercanas a todos los sectores de la sociedad, se quedaran fuera de esta nueva sociedad digital. Existen ejemplos muy interesantes de servicios de información web proporcionados por pequeñas y medianas bibliotecas municipales que no tienen nada que envidiar a las grandes bibliotecas provinciales, regionales o nacionales. Sería el caso, por ejemplo, de las bibliotecas municipales de Jerez de la Frontera y de Móstoles.

(3) El reto tecnológico que supone la creación de un SIW en una biblioteca pública no está siendo, al menos en el caso español, llevado a cabo de una manera uniforme, pues aún son muchas las bibliotecas públicas, en especial las de carácter municipal, que mantienen sus procesos y recursos de información basados exclusivamente en modelos de trabajo tradicionales y anclados en el pasado. En estos casos, bien por recortes presupuestarios, bien por la dejadez e incompetencia del profesional, se considera la relación con Internet y la puesta en marcha de un SIW como algo lejano, de difícil acceso y complicado manejo, como una tarea reservada a especialistas en informática y caro de mantener. Ni mucho menos. Desarrollar una SIW no es muy complejo, las herramientas para hacerlo son de fácil manejo y su instalación y mantenimiento es de bajo coste.

(4) La función tradicional de la biblioteca pública como centro de distribución de información sigue siendo muy importante, puesto que la aportación de las tecnologías de la información en estas unidades de información y documentación las capacita para proporcionar información de interés comunitario. Puede darse información municipal de carácter administrativo, de suma utilidad para los ciudadanos; o mantener una agenda cultural de la comarca; e incluso, editar electrónicamente materiales de interés folklórico, artístico o sobre personalidades peculiares de la localidad, y todo ello con un coste no muy considerable (García Gómez y Díaz Grau, 2000 y 2001).

(5) Cuando hablamos de usabilidad nos referimos a si el sistema de navegación y presentación de información del SIW permite un fácil acceso y uso de los contenidos. Ahora bien, no confundamos una buena usabilidad del sistema con un buen diseño gráfico del mismo, pues son dos cosas totalmente distintas, ya que un diseño gráfico atractivo y bonito ni mucho menos asegura una buena usabilidad de los recursos que ofrece el SIW de la biblioteca. En este sentido, una buena usabilidad debe permitir solucionar, entre otros, el principal problema relacionado con los contenidos informativos del web: las dificultades experimentadas por los usuarios a la hora de navegar por la información en un entorno web determinado.

(6) En el ciberespacio no hay distancia, no tengo que ir a la biblioteca de mi barrio porque está más cerca. Puedo consultar la nacional de Washington si tarda menos en descargarse y también soluciona mi solicitud de información.

(7) En este sentido, la información está bien diseminada por todo el web, no se repite la misma sino que se complementa yendo mediante enlaces internos de un lugar a otro según el grado de necesidad de información. Aunque parezca esto de cajón, no en todos los sitios se aprovechan de esta característica fundamental, el carácter de hipertexto.

Scire. $8: 2$ (jul.-dic. 2002) 91-116. 
(8) El Proyecto Jumilla concibe el desarrollo de un sistema integrado de información local desde una triple perspectiva: extensión bibliotecaria y actividades relacionadas, servicio de información turística y creación de un servicio de información sobre la Unión Europea. Como nodo central de este sistema actúa la biblioteca pública municipal, principal servicio de información de la población, desde donde se coordinarán las actividades de este proyecto, bien aquellas que sean fruto de una política de extensión bibliotecaria, bien aquellas que partan de cero. Estamos, pues, ante un sistema integrado de información local cuyo objetivo es especializarse en proporcionar a los ciudadanos información y documentación cultural, turística y comunitaria, aprovechando las sinergias que se derivaran de una acción conjunta e integradora de desarrollo, optimizando la inversión de recursos por parte de las instituciones municipales y favoreciendo el acceso de los usuarios a la Sociedad de la Información.

(9) Véase a tal respecto, la información existente en http://gti1.edu.um.es:8080/portales/FGSR-portales-Bibliotecas.PDF.

(10) Una selección de criterios para la evaluación de recursos digitales aparecen recogidos en los trabajos de Codina (2000).

\section{Referencias bibliográficas}

Amat i Noguera, Nuria (1990). La biblioteca electrónica. Madrid: Pirámide, 1990.

Aguilló, Isidro F.(2000). Bibliotecas sin paredes: construyendo las nuevas bibliotecas digitales virtuales. // Jornadas Bibliotecarias de Andalucía. 9 (2000) 143-149.

Agustín Lacruz, María Carmen (1998). Bibliotecas digitales y sociedad de la información. // Scire. 4:2 (jul.-dic. 1998) 47-62.

Batt, Chris (1995). La biblioteca del futuro: las bibliotecas públicas e Internet. // Boletín de la Asociación Andaluza de Bibliotecarios. 11:41 (dic. 1995) 39-47.

Codina, Lluís (2000a). Evaluación de recursos digitales en línea: conceptos, indicadores y métodos. // Revista Española de Documentación Científica. 23:1 (2000) 9-44.

Codina, Lluís (2000b). Parámetros e indicadores de calidad para la evaluación de recursos digitales. // VII Jornadas Españolas de Documentación. Bilbao: FESABID, 2000. 135-144.

Colodrón, Victoriano (1998). Las Bibliotecas Públicas y la Sociedad de la Información: España. // Las Bibliotecas Públicas y la Sociedad de la Información. Luxemburgo: Oficina de Publicaciones Oficiales de las Comunidades Autónomas, 1998. 163-176.

García Gómez, Fco. Javier; Díaz Grau, Antonio (2000a). La difusión de información en la biblioteca publica: el servicio de información local en bibliotecas publicas municipales. // Educación y Biblioteca.117 (nov. 2000) 36-39.

García Gómez, Fco. Javier; Díaz Grau, Antonio (2000b). Biblioteca pública, información local y difusión de información: reflexiones acerca de un servicio de información local. // Revista TK. 10 (dic. 2000) 107-113.

García Gómez, Fco. Javier; Díaz Grau, Antonio (2000c). El servicio de información local en las bibliotecas publicas municipales. Importancia y pautas para su desarrollo (I). // Boletín de la Asociación Andaluza de Bibliotecarios. 15:61 (diciembre 2000) 47-56. URL: <http://www.aab.es/51n61a3.pdf>.

Scire. $8: 2$ (jul.-dic. 2002) 91-116. 
García Gómez, Fco. Javier; Díaz Grau, Antonio (2001). El servicio de información local en las bibliotecas publicas municipales. Importancia y pautas para su desarrollo (II). // Boletín de la Asociación Andaluza de Bibliotecarios:62 (marzo 2. 001) 31-47. URL: <http://www.aab.es/51n62a2.pdf>.

García Maza, Julia (1998). Sistemas de Información: lugar de encuentro entre el desafío tecnológico y el pensamiento social. // VI Jornadas Españolas de Documentación. Valencia: FESABID, 1998. 345-350. URL: <http://fesabid98.floridauni.es/Comunicaciones/j_garcia.htm>.

Hípola, Pedro; Vargas-Quesada, Benjamín; Senso, José A. (2000). Bibliotecas digitales: situación actual y problemas. // El Profesional de la Información. 9:4 (abril 2000) 4-13.

Lozano, Roser (1999). Introducción a la Biblioteca Pública Virtual. Una nueva biblioteca para una nueva sociedad. // Educación y Biblioteca. 106 (nov. 1999) 72-76.

Lloret, Nuria (1999). La situación de las Bibliotecas en España. El reto de la Biblioteca real y la Biblioteca Digital. // Métodos de Información. 6:31 (jul. 1999) 62-65.

Mano González, Marta de la; Moro Cabero, Manuela (1998). Los nuevos retos de la formación de usuarios: a la conquista del usuario virtual. // VI Jornadas Españolas de Documentación. Valencia: FESABID, 1998. URL: <http://fesabid98.floridauni.es/Comunicaciones/m_moro/m_moro.htm>.

Méndez Rodríguez, Eva María (1999). Las Bibliotecas Públicas Españolas en la web: ¿qué información ofrecen nuestras bibliotecas públicas en la Red?. // Educación y Biblioteca:106 (noviembre 1999) 48-54. URL: <http://rayuela.uc3m.es/ mendez/ publicaciones/articulos/bibpcas99. pdf>.

Muñoz Cañavate, Antonio; Chaín Navarro, Celia (1999). Los Sistemas de Información Web como elemento de difusión de información. Análisis y evaluación de las prestaciones ofrecidas. // IV Congreso ISKO-España. Granada: EOCONSID, 1999. 277-288.

Muñoz Gómez, María; Rubiano Montaño, Penélope (1998). El bibliotecario digital: el perfil de un nuevo profesional de la información. // VI Jornadas españolas de Documentación. Valencia: FESABID, 1998. 661-664. URL: <http://fesabid98.florida-uni.es/Comunicaciones/m_munyoz.htm>.

Pérez Alarcón, Adoració (1999). La biblioteca digital. // Anuari de Biblioteconomía i Documentació. Barcelona: COBDC, 1999. 75-88.

Pinto Escribano, Joaquín (1997). Biblioteca virtual y usuarios remotos. // Boletín AABADOM. 3 (jul.-sept. 1997) 38-45.

Térmens i Graells, Miquel (1997). Les webs de les biblioteques de Catalunya: Estructura interna y enllaÇos. // 6es Jornades Catalanes de Documentació. Barcelona: SOCADI, 1997. 507-517. 